Polymorphisms and malaria

\section{Apolipoprotein E polymorphisms and risk of malaria}

\section{A Wozniak, E M Riley, R F Itzhaki}

$\mathrm{H}$ ost genetic factors probably determine both susceptibility to infection and severity of damage by pathogens. A large number of polymorphisms have now been implicated in the onset, progression, and outcome of malaria infection, seeming to influence the ability of the host immune response to control the infection. These include:

- those associated with haemoglobinopathies $^{1}$

- those within the major histocompatibility complex (HMC), including HLA class I and class II and the tumour necrosis factor promoter

- those within genes not associated with HMC, such as ICAM-1, CD36, and possibly the gene for nitric oxide synthase ${ }^{2}$

- probably the gene for apolipoprotein E (APOE), as our recent data suggest, and upon which we comment below. ${ }^{3}$

APOE has three main alleles, types 2 , 3, and 4, resulting in six possible genotypes; it codes for the protein apoE, which is involved in transport of lipids in the blood and the central nervous system.

Finding that APOE- $\varepsilon 2$ homozygous Ghanaian infants were more likely to be infected with the malaria protozoon at a very young age than those with the other genotypes, we predicted that severity of illness after infection might depend to some extent on APOE genotype. ${ }^{3}$ In this issue, the article by Aucan et al offers support for involvement of APOE in the development of severe malaria: people carrying an APOE- $83 /$ \&4 genotype may be more likely than those with the other main genotypes to suffer extremely severe malaria (cerebral malaria and severe anaemia). Our prediction stemmed from previous observations that APOE determines outcome of infection, rather than susceptibility to infection, by three very diverse pathogens:

- herpes simplex virus type l (HSVl) in cold sores $^{45}$ and herpes simplex encephalitis $^{6}$
- hepatitis $C$ virus in liver damage ${ }^{7}$

- HIV in dementia and peripheral neuropathy occurring before the development of AIDS. ${ }^{8}$

These studies followed our previous discovery that HSVl resides in a high proportion of elderly human brains," and that in APOE- $\varepsilon 4$ carriers this virus confers a strong risk of Alzheimer's disease. $^{45}$ We tentatively suggested ${ }^{5}$ an explanation based on the usage by each of these viruses, ${ }^{710}$ and by the malaria protozoon, ${ }^{3}$ of the same cell entry mediators as those of apoE. These mediators include surface binding sites (heparan sulphate proteoglycans or HSPG) and/or receptors (one of the low density lipoprotein receptor family). Thus, apoE might compete with the pathogens for entry into cells, and any difference in isoform affinity for the binding sites/receptors could affect the extent of competition and hence of pathogen entry, spread, and damage. In fact, apoE isoforms do have different affinities for certain cells ${ }^{11}{ }^{12}$ : with hepatoma cells apoE4 has the least affinity, whereas with fibroblasts there are no differences. ${ }^{11}{ }^{12}$ This might explain why a specific allele is protective in some cases $^{7}$ but harmful, ${ }^{3-68}$ or else neutral, ${ }^{13}$ in others.

Competition between ApoE and the protozoon might be a factor also in very severe malaria. ApoE isoforms may vary in their ability to compete with malaria sporozoites for binding to hepatocytes, thereby affecting parasite load in the liver, the density of forms of the parasite in the blood, and thus the severity of the disease.

Severe malaria is also associated with changes in adhesive properties of infected erythrocytes to endothelial cells and with rosetting, both of which cause obstructions in brain microvasculature; these processes, as well, involve cell surface HSPG. ${ }^{14}$ Thus, as described above, apoE isoforms might affect-via HSPG - the rate or extent of spread of the parasite in erythrocytes and the consequent adhesive changes in these cells. Alternatively, differences in plasma level of apoE and/or lipoproteins that are known to occur in the different genotypes might affect erythrocyte adhesion.

Our discovery that APOE- $\varepsilon 2$ homozygotes are infected at a very early age is not inconsistent with the finding of Aucan et al that APOE- $\varepsilon 3 / \varepsilon 4$ carriers are more likely to suffer extremely severe malaria. Epidemiological studies ${ }^{15}$ suggest that the risk of developing severe malaria is lower in children who experience their first malaria infections very early in life than in those first infected at an older age. Presumably, children infected during infancy (while still protected from clinical malaria and high parasitaemia by innate protective mechanisms and maternal antibodies) develop adaptive immune responses that protect them from severe disease in later life. On the other hand, those infected only later (after the protective mechanisms of infancy have waned) are fully susceptible and at high risk of severe or fatal disease. Thus, the earlier the infection occurs (as in 82 homozygotes), the less the likelihood of lifethreatening illness. Indeed, in the study by Aucan et al, APOE- $\varepsilon 2$ carriers were under-represented in the extremely severe malaria (cerebral malaria with severe anaemia) group (7.1\% $v \quad 11.5-$ $13.8 \%$ in the other groups), although the difference does not reach statistical significance.

Whatever the explanation for the results of Aucan et al, our data and theirs add to the extraordinarily diverse repertoire of infective diseases in which APOE determines outcome of, or susceptibility to, infection; and they suggest the possible use of this information for prognostic purposes.

J Med Genet 2004;41:145-146. doi: 10.1136/jmg.2003.014613

\section{Authors' affiliations}

M A Wozniak, R F Itzhaki, Department of Optometry \& Neuroscience, UMIST, Manchester, UK

E M Riley, Department of Infectious and Tropical Diseases, London School of Hygiene and Tropical Medicine, UK

Correspondence to: $\operatorname{Dr} M$ A Wozniak, Molecular Neurobiology Laboratory, Department of Optometry and Neuroscience, UMIST, Manchester M60 1QD, UK; matthew.a.wozniak@umist.ac.uk

\section{REFERENCES}

1 Weatherall DJ, Clegg JB. Genetic variability in response to infection: malaria and after. Genes Immun 2002;3:331-7.

2 Fortin A, Stevenson MM, Gros P. Susceptibility to malaria as a complex trait: big pressure from a tiny creature. Hum Mol Genet 2002; 1 1:2469-78.

3 Wozniak MA, Faragher BE, Todd JA, Koram KA, Riley EM, Itzhaki RF. Does apolipoprotein E polymorphism influence susceptibility to malaria? J Med Genet 2003;40:348-51 
4 Lin WR, Graham J, MacGowan SM, Wilcock GK, Itzhaki RF. Alzheimer's disease, herpes virus in brain, apolipoprotein E4 and herpes labialis. Alzheimers Reports 1998:1:173-8.

5 Itzhaki RF, Lin WR, Shang D, Wilcock GK Faragher B, Jamieson GA. Herpes simplex virus type 1 in brain and risk of Alzheimer's disease. Lancet 1997:349:241-4.

6 Lin WR, Wozniak MA, Esiri MM, Klenerman P, Itzhaki RF. Herpes simplex encephalitis: involvement of apolipoprotein E genotype. J Neurol Neurosurg Psychiatry 2001;70:117-19.

7 Wozniak MA, Itzhaki RF, Faragher EB, James MW, Ryder SD, Irving WL. Apolipoprotein E-epsilon 4 protects against severe liver disease caused by hepatitis $C$ virus. Hepatology 2002;36:456-63.
8 Corder EH, Robertson K, Lannfelt L, Bogdanovic N, Eggertsen G, Wilkins J, Hall C. HIV-infected subjects with the E4 allele for APOE have excess dementia and peripheral neuropathy. Nat Med 1998;4:1182-4

9 Jamieson GA, Maitland NJ, Wilcock GK, Craske J, Itzhaki RF. Latent herpes simplex virus type 1 in normal and Alzheimer's disease brains. J Med Virol 1991;33:224-7.

10 Itzhaki RF, Wozniak M, Dobson C, Lin WR. ApoE-viral interactions. Nat Med 1998;4:1344.

11 Bohnet K, Pillot T, Visvikis S, Sabolovic N, Siest G. Apolipoprotein (apo) E genotype and apoE concentration determine binding of normal very low density lipoproteins to HepG2 cell surface receptors. J Lipid Res 1996;37:1316-24.
12 Mamotte CD, Sturm M, Foo Jl, van Bockxmeer FM, Taylor RR. Comparison of the $\mathrm{LDL}$-receptor binding of VLDL and LDL from apoE4 and apoE3 homozygotes. Am J Physiol 1999:276:E553-7.

13 Lin WR, Tullo AB, Itzhaki RF. Apolipoprotein E and herpes virus diseases: herpes simplex keratitis. Eur J Hum Genet 1999:7:401-3.

14 Kisilevsky R, Crandall I, Szarek WA, Bhat S, Tan C, Boudreau L, Kain KC. Short-chain aliphatic polysulfonates inhibit the entry of Plasmodium into red blood cells. Antimicrob Agents Chemother 2002:46:2619-26.

15 Gupta S, Snow RW, Donnelly CA, Marsh K, Newbold C. Immunity to non-cerebral severe malaria is acquired after one or two infections. Nat Med 1999;5:340-3.

\section{CORRECTION}

doi: 10.1136/jmg.2003.014613corr 1

This commentary should have been published alongside the article "Common apolipoprotein E polymorphisms and risk of clinical malaria in The Gambia" by $\mathrm{C}$ Aucan, AJ Walley, and AVS Hill in the January 2004 issue ( $\mathrm{J}$ Med Genet 2004;41:2124). This error is much regretted and we would like to offer our sincere apologies to the authors involved. 